\title{
The ABCs' of mantle metasomatism in the North Atlantic Craton mirrored in fluid microinclusions in Chidliak $\mathrm{CH}$ - 7 diamonds.
}

\author{
ODED ELAZAR ${ }^{1}$, YAAKOV WEISS ${ }^{2}$ AND HERMAN \\ GRÜTTER $^{3}$ \\ ${ }^{1}$ The Hebrew University of Jerusalem \\ ${ }^{2}$ The Hebrew University \\ ${ }^{3}$ SRK Consulting (Canada) \\ Presenting Author: odedelazar10@gmail.com
}

More than 800 kimberlite bodies are known in Canada. Among these $>70$ kimberlites were recently discovered at Chidliak, a new diamond district on the Hall Peninsula of southern Baffin Island, Nunavut. Here we report the compositional variation of microinclusions carrying high-density supercritical fluids (HDFs) in a suite of diamonds from the $\sim 142$ Ma Chidliak CH-7 kimberlite pipe. The HDFs vary within the silicic to low-Mg carbonatitic composition array, which was attributed to an eclogitic mantle source. Within the studied diamonds, we observe three populations based on the chemistry of the encapsulated HDFs, the diamond's nitrogen aggregation states, and their color. 'Group $\mathrm{Ib} / \mathrm{IaA}$ ' diamonds contain highly silicic HDFs, have nitrogen in A- and C-centers (with 5-20\% Ccenter) and a characterizing intense yellow color. 'Group IaA' diamonds contain silicic to low-Mg carbonatitic HDFs, carry nitrogen solely in A-centers, and are mostly translucent. The third population, 'Group IaAB', has distinguished low- $\mathrm{K}_{2} \mathrm{O}$ silicic to low-Mg carbonatitic compositions and overall smoother and less fractionated primitive mantle normalized trace element pattern relative to Group $\mathrm{Ib} / \mathrm{IaA}$ and IaA diamonds; they carry nitrogen in A- and B-centers (with $\sim 15 \%$ B-centers) and are characterized by a gray hue. These differences indicate diamond formation during different metasomatic events, which we correlate with the various lithospheric extension episodes in the North Atlantic Craton (NAC) since the Proterozoic. Based on major and trace element similarities, we suggest a genetic relation between the formation of Group IaAB diamonds and old metasomatism relating to olivine lamproites volcanism ca. 1400 Ma. The event in which Group Ia/A diamond formed could take place ca. $600 \mathrm{Ma}$, preceding aillikite/carbonatitic volcanism (590-555 Ma, western Greenland). Group Ib/IaA formed very close to the Chidliak kimberlite activity between 142-157 Ma, during a related metasomatic event. Our new data thus reveal three distinct metasomatic episodes by silicic to low-Mg carbonatitic over the last 1.5 Ga history of the NAC. In addition, based on recent experimental results, we suggest a possible link between the highly silicic HDFs characterizing the last event and the formation of a mid lithosphere discontinuity in the NAC. 